\title{
Carnitine Status in Early-Treated Children, Adolescents and Young Adults with Phenylketonuria on Low Phenylalanine Diets
}

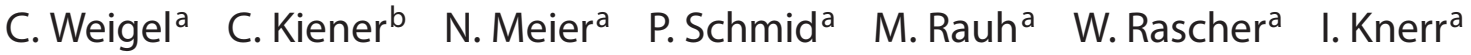

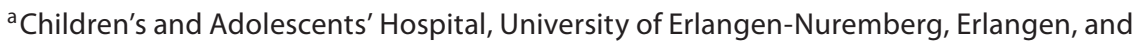 \\ bSHS Company, Heilbronn, Germany
}

Key Words

Acylcarnitines $\cdot$ Carnitine $\cdot$ Diet $\cdot$ Phenylketonuria

\begin{abstract}
Background: In patients with phenylketonuria (PKU), the carnitine status may be impaired for metabolic or dietary reasons, including low carnitine intake, a deficient synthesis and acylcarnitine production from phenylalanine (Phe) metabolites. Methods: Free carnitine and acylcarnitine status was assessed in $30 \mathrm{PKU}$ patients, aged $0.5-36$ years, mean age 13.8 years. Our cohort was divided into 2 groups according to the preparations of Phe-free amino acids (AA) prescribed, with or without carnitine supplementation. Daily Phe intake, dosage of AA mixtures and body weight were recorded along with measurements of acylcarnitines in blood spots (by tandem mass spectrometry) and serum AA. Control data were obtained from 50 healthy volunteers (aged 0.2-39 years, mean age 14.2. years). Statistical analysis comprised the t test, ANOVA and Pearson's correlation. $\boldsymbol{R e}$ sults: PKU patients had lower free carnitine (C0) concentrations than controls $\left(25.82 \pm 7.38\right.$ vs. $31.28 \pm 6.17 \mu \mathrm{mol} / \mathrm{l}_{;}$ $\mathrm{p}<0.001$ ) and lower octanoyl- and decanoylcarnitine. Mean $\mathrm{CO}$ and acylcarnitine concentrations did not differ between PKU patients taking the various protein substitutes with or without carnitine; mean CO levels in PKU patients receiving
\end{abstract}

AA enriched with carnitine were still lower compared with controls $(p<0.05)$. Conclusions: Actual dietary regimens can not completely normalize the carnitine status; therefore, carnitine levels should be given careful consideration in subjects with PKU.

Copyright ๑ 2008 S. Karger AG, Basel

\section{Introduction}

Carnitine is an obligatory factor for fatty acid degradation, as it facilitates the transport of long-chain fatty acids across the inner mitochondrial membrane for beta oxidation. In addition to free carnitine ( $\mathrm{C} 0$ ), short-, mediumand long-chain acylcarnitines are determined in, for example, dried blood spots. A decrease in carnitine concentrations and changes in the acylcarnitine profile may be found in various inborn errors of metabolism, such as fatty acid oxidation defects, and in various diseases affecting the liver or kidney function. Moreover, special diets, particularly vegan diets, may contribute to nutritional carnitine deficiency.

Phenylketonuria (PKU) is an inherited metabolic disorder that results in high plasma phenylalanine (Phe) concentrations and has been treated for more than 50 years by low Phe diet in order to prevent neurological

\section{KARGER \\ Fax +4161306 1234 E-Mail karger@karger.ch} www.karger.com
() 2008 S. Karger AG, Basel

0250-6807/08/0532-0091\$24.50/0

Accessible online at:

www.karger.com/anm
Ina Knerr, MD

Children's and Adolescents' Hospital, University of Erlangen-Nuremberg

Loschgestrasse 15

DE-91054 Erlangen (Germany)

Tel. +49 913185 33118, Fax +499131 85 33113, E-Mail ina.knerr@uk-erlangen.de 
damage. In patients with PKU, the carnitine status may be impaired for metabolic or dietary reasons such as low carnitine intake, deficient carnitine synthesis and acylcarnitine production such as phenacetyl-carnitine [1]. It has been reported that patients with PKU on a Phe-restricted diet without carnitine supplementation have lower serum concentrations of free, esterified and total carnitine, but the clinical symptoms of carnitine deficiency, such as muscle weakness or cardiomyopathy, were not observed in these patients [2-4]. Patients with high plasma Phe concentrations and, subsequently, accumulation of its pathological metabolites may be particularly at risk, because phenylacetic acid is capable of inhibiting the endogenous carnitine synthesis [1]. Moreover, it has been suggested that an altered metabolism of long-chain polyunsaturated fatty acids, such as arachidonic and docosahexaenoic acids, contributes to the neurological deterioration in subjects with untreated PKU [5]. It is of interest that these fatty acids are handled by carnitine-dependent desaturases, and their cofactor $\alpha$-tocopherolquinone can be inhibited by phenylpyruvic and phenyllactic acid [5].

We focused on the adequacy of the PKU diet for maintaining a normal carnitine status in patients taking Phefree amino acid (AA) supplements with or without carnitine supplementation.

\section{Methods}

Thirty early-treated children, adolescents and young adults with classical PKU, aged $0.5-36$ years (mean age 13.8 years, 53\% females), were recruited from the Children's and Adolescents' Hospital, University of Erlangen-Nuremberg. The study protocol had been approved by the local ethics committee, and informed consent was obtained. Subjects reported after overnight fast and younger children 3-4 h after their last meal. Our cohort was divided into 2 subgroups of comparable age according to the Phefree AA mixture prescribed. Group A $(n=17)$ received AA preparations (SHS p-am $2^{\circledR}$ and SHS p-am $3^{\circledR}$ ), which did not contain carnitine, whereas group B ( $=13)$ was treated with comparable Phe-free protein substitutes supplemented with carnitine (up to $68 \mathrm{mg} / 100 \mathrm{~g}$ powder; table 1). In the latter, additional carnitine intake was up to $5 \mu \mathrm{mol} / \mathrm{kg}$ body weight per day, comparable with a normal dietary intake by mixed Western diets [6]. The diet was adjusted for age, body weight and metabolic state, including serum Phe, tyrosine and other AA. During visits at our outpatient clinic, daily Phe intake and the dosage of Phe-free substitutes were documented, as reported by the parents or adult patients. Body weight was measured with calibrated devices. Acylcarnitines were analyzed in dried blood spots by tandem mass spectrometry [7]; AA analysis was carried out as reported previously [8]. Briefly, samples were deproteinized with a $10 \%$ sulfosalicylic acid solution. Thereafter, AA were determined with an AA analyzer (Biotronic LC 3000, Eppendorf, Maintal, Germany) with postcolumn derivatization with ninhydrine.

Age-matched control data obtained from 50 healthy volunteers (aged $0.2-39$ years, mean age 14.2 . years, $48 \%$ females) were used for comparison. No patient or volunteer received additional carnitine supplements.

Table 1. Composition of PKU formula (energy, macronutrient, AA, carnitine and iron) for the different age groups

\begin{tabular}{|c|c|c|c|c|}
\hline \multirow[t]{2}{*}{$\begin{array}{l}\text { Ingredients } \\
\text { (per } 100 \mathrm{~g} \text { powder) }\end{array}$} & \multicolumn{2}{|c|}{$\begin{array}{l}\text { Group A } \\
\text { (PKU products without carnitine) }\end{array}$} & \multicolumn{2}{|c|}{$\begin{array}{l}\text { Group B } \\
\text { (PKU products with carnitine) }\end{array}$} \\
\hline & $\begin{array}{l}<12 \text { years } \\
(\text { SHS p-am 2) }\end{array}$ & $\begin{array}{l}>12 \text { years } \\
\text { (SHS p-am } 3)\end{array}$ & $<14$ years & $>14$ years \\
\hline Energy, kcal & 300 & 300 & 300 & 309 \\
\hline Protein, g & 75 & 75 & 75 & 77 \\
\hline Carbohydrates, g & 0 & 0 & 0 & 0 \\
\hline Fat, g & 0 & 0 & 0 & 0 \\
\hline L-Methionine, $\mathrm{g}$ & 1.6 & 1.6 & 1.5 & 1.4 \\
\hline L-Isoleucine, $g$ & 4.5 & 4.5 & 4.8 & 4.6 \\
\hline L-Leucine, $g$ & 6.8 & 6.7 & 8.1 & 7.7 \\
\hline L-Tyrosine, $\mathrm{g}$ & 6.2 & 7.0 & 6.8 & 8.1 \\
\hline L-Tryptophane, g & 1.3 & 1.2 & 1.7 & 1.6 \\
\hline L-Valine, $g$ & 5.7 & 5.4 & 5.6 & 6.3 \\
\hline L-Lysine, $\mathrm{g}$ & 5.5 & 5.4 & 6.2 & 5.5 \\
\hline L-Threonine, $g$ & 3.9 & 4.0 & 4.1 & 4.7 \\
\hline Carnitine, mg & 0 & 0 & 68 & 54 \\
\hline Iron, $\mathrm{mg}$ & 23 & 20 & 27 & 23 \\
\hline
\end{tabular}

The products also contain trace elements, minerals and vitamins (not shown). 
Data were analyzed using Graph Pad Prism software 4.0 (San Diego, Calif., USA) and SPSS 14.0 (Chicago, Ill., USA). Groups were compared using the t test, analysis of variance (ANOVA) and Pearson's correlation, if applicable; differences were considered significant at $\mathrm{p}<0.05$.

\section{Results}

Patients with PKU had significantly lower C0 concentrations and a larger range of $\mathrm{C} 0$ levels compared with controls (mean C0 $25.82 \pm 7.38$ vs. $31.28 \pm 6.17 \mu \mathrm{mol} / \mathrm{l}$, $\mathrm{p}<0.001$, range $12.37-40.09$ vs. $20.74-45.08 \mu \mathrm{mol} / \mathrm{l}$; table 2). Concentrations of octanoyl- and decanoylcarnitine were lower in the entire PKU cohort compared with controls (table 2), but no significant differences were found for acetylcarnitine, hexanoyl-, myristoyl-, palmitoyl-, stearoyl-, and linoleoylcarnitine concentrations. Serum tyrosine and methionine concentrations were lower in PKU patients compared with controls (table 2). In the entire PKU cohort, mean serum Phe was $432 \pm$ $328 \mu \mathrm{mol} / 1$ (range 12-1,180), mean reported daily Phe intake was $397 \pm 156 \mathrm{mg}$ (range $170-800 \mathrm{mg}$ ), and mean total protein intake was $1.3 \pm 0.3 \mathrm{~g} / \mathrm{kg}$ body weight per day. For patients with PKU on a low Phe diet, there was a significant correlation between lysine und methionine serum concentrations $(\mathrm{r}=0.4501, \mathrm{p}<0.05)$. Mean Phe and tyrosine serum concentrations did not significantly differ between the 2 PKU subgroups, nor did the lysine and methionine concentrations (table 3 ).

It is of interest that mean C0 and acylcarnitine concentrations did not differ between PKU patients taking the various Phe-free protein substitutes with or without

Table 2. Acylcarnitines in dried blood spots and serum AA in subjects with PKU and healthy controls

\begin{tabular}{lccc}
\hline Measure & PKU $(\mathrm{n}=30)$ & Controls $(\mathrm{n}=50)$ & $\mathrm{p}$ value \\
\hline C0 & $25.82 \pm 7.38$ & $31.28 \pm 6.17$ & $<0.001$ \\
C2 & $17.35 \pm 6.45$ & $17.54 \pm 9.77$ & n.s. \\
C6 & $0.04 \pm 0.02$ & $0.05 \pm 0.02$ & n.s. \\
C8 & $0.06 \pm 0.04$ & $0.10 \pm 0.05$ & $<0.001$ \\
C10 & $0.09 \pm 0.07$ & $0.17 \pm 0.11$ & $<0.01$ \\
C14 & $0.13 \pm 0.05$ & $0.15 \pm 0.05$ & n.s. \\
C16 & $1.01 \pm 0.34$ & $1.15 \pm 0.33$ & n.s. \\
\hline Phe & $432 \pm 328$ & $51 \pm 17$ & $<0.001$ \\
Tyr & $67 \pm 31$ & $78 \pm 6$ & $<0.05$ \\
Lys & $176 \pm 64$ & $184 \pm 14$ & n.s. \\
Met & $23 \pm 11$ & $31 \pm 4$ & $<0.01$ \\
\hline
\end{tabular}

Data are given as the mean $\pm \mathrm{SD}$; concentrations are given in $\mu \mathrm{mol} / \mathrm{l}$. n.s. $=$ Not significant.

Table 3. Patients' age, daily Phe and protein intake, acylcarnitine levels in dried blood spots and serum AA concentrations

\begin{tabular}{lccc}
\hline Measure & Group A $(\mathrm{n}=17)$ & Group B $(\mathrm{n}=13)$ & p value \\
\hline Age, years & $13.9 \pm 10.7$ & $13.8 \pm 10.3$ & n.s. \\
Phe intake, mg/day & $402 \pm 184$ (range 170-800) & $392 \pm 145$ (range 250-700) & n.s. \\
$\begin{array}{l}\text { Protein intake, g/kg body weight } \\
\quad \text { per day }\end{array}$ & $1.3 \pm 0.3$ & $1.3 \pm 0.3$ & n.s. \\
\hline C0 & $22.60 \pm 6.24$ & $27.10 \pm 6.12$ & n.s. $^{\text {a }}$ \\
C8 & $0.06 \pm 0.05$ & $0.06 \pm 0.02$ & n.s. $^{\text {b }}$ \\
C10 & $0.10 \pm 0.09$ & $0.08 \pm 0.04$ & n.s. ${ }^{\text {a }}$ \\
\hline Phe & $357 \pm 319($ range 12-1,180) & $513 \pm 322($ range 164-1,110) & n.s. \\
Tyr & $66.1 \pm 23.8$ & $68.8 \pm 25.7$ & n.s. \\
Lys & $173.4 \pm 67.2$ & $177.7 \pm 59.9$ & n.s. \\
Met & $23.8 \pm 14.0$ & $22.5 \pm 5.7$ & n.s. \\
\hline
\end{tabular}

Subjects are divided into 2 groups: group A received dietary AA preparations without carnitine, and group B received various dietary products with a low-dose carnitine content (up to $68 \mathrm{mg} / 100 \mathrm{~g}$ powder). Data are given as the mean $\pm \mathrm{SD}$; concentrations are given in $\mu \mathrm{mol} / \mathrm{l}$. Comparison between the PKU groups is shown, unless otherwise stated.

${ }^{a}$ PKU subgroup B significantly different from the control group $(\mathrm{p}<0.05)$.

${ }^{\mathrm{b}}$ PKU subgroup B significantly different from the control group $(\mathrm{p}<0.01)$. 
carnitine (table 3). Mean C0 concentrations in PKU patients receiving $\mathrm{AA}$ enriched with carnitine were still lower compared with controls (C0 $27.10 \pm 6.12$ vs. 31.28 $\pm 6.17 \mu \mathrm{mol} / \mathrm{l} ; \mathrm{p}<0.05)$. Octanoylcarnitine was also significantly reduced in group $\mathrm{B}$ compared with controls $(0.06 \pm 0.02$ vs. $0.10 \pm 0.05 ; p<0.01)$, as was decanoylcarnitine $(0.08 \pm 0.04$ vs. $0.17 \pm 0.11 ; \mathrm{p}<0.05)$.

\section{Discussion}

Generally, the PKU diet is characterized by a restricted diversity of foodstuffs. Although in the lower normal range, $\mathrm{C} 0$ concentrations in the blood of patients with PKU on a diet were significantly lower compared with controls. This indicates that actual dietary regimens cannot completely normalize carnitine status in subjects with PKU. There are several possible explanations for this finding. It has been described earlier that protein content may exert considerable effects on carnitine glomerular filtration, excretion and reabsorption. The rate of carnitine reabsorption, for example, was lower after ingestion of a low-protein load than after a high-protein load [9]. However, the rate of carnitine excretion was also lower after ingestion of a low-protein diet due to a lower glomerular filtration rate, compared with a high-protein intake $[9,10]$. It is also possible that the activity of the main carnitine transporter, OCTN2, may differ between patients, which results in different carnitine levels.

In addition to dietary effects regarding the macronutrient content, another explanation may be the bioavailability of carnitine in the AA preparations and possible degradation of carnitine in the gastrointestinal tract [11]. Moreover, we found that serum methionine concentrations were slightly lower in PKU patients compared with controls, which is indicative of the ongoing need to improve AA substitution in Phe-restrictive diets. Basically, carnitine homeostasis is maintained by intestinal ab- sorption, endogenous synthesis and renal reabsorption. Circulating carnitine is distributed to muscle, the liver, the kidneys and other organs. Skeletal muscle, in particular, is, kinetically, a large and slow-turnover compartment [11]. Considering the necessity of lysine and methionine for the hepatic carnitine biosynthesis, it is extremely important to guarantee adequate AA supplementation in subjects with PKU on Phe-restrictive diets, not only because of protein anabolism. The availability of the intermediate trimethyllysine stored in skeletal muscle and its transport across the mitochondrial inner membrane is a rate-limiting step in carnitine biosynthesis [12]; therefore, protein anabolism, which in general is essential for maintaining metabolic compensation in aminoacidopathies such as PKU, is a key mechanism for optimal carnitine biosynthesis. Besides lysine and methionine, iron and vitamin $\mathrm{B}_{6}$ are required in endogenous carnitine synthesis [13]. Therefore, we cannot rule out the possibility that low intakes of iron and vitamin $\mathrm{B}_{6}$ could contribute to a reduced biosynthesis and compromised carnitine status in subjects with PKU.

Due to methodological reasons, data on tissue carnitine concentrations are lacking in subjects with PKU, but careful consideration should be given to blood carnitine levels in order to optimize carnitine status and prevent carnitine deficiency in patients at risk. A preventative supplementation with carnitine may have therapeutic value for PKU patients who have a low carnitine status but higher demands, e.g. women with PKU during pregnancy. In conclusion, further optimization of the PKU diet regarding carnitine intake should be considered.

\section{Acknowledgements}

We are indebted to the patients and healthy volunteers for their collaboration.

\section{References}

1 Fischer GM, Nemeti B, Farkas V, et al: Metabolism of carnitine in phenylacetic acidtreated rats and in patients with phenylketonuria. Biochim Biophys Acta 2000;1501: 200-210.

2 Vilaseca MA, Briones P, Ferrer I, et al: Controlled diet in phenylketonuria may cause serum carnitine deficiency. J Inherit Metab Dis 1993;16:101-104.
3 Bohles H, Ullrich K, Endres W, Behbehani AW, Wendel U: Inadequate iron availability as a possible cause of low serum carnitine concentrations in patients with phenylketonuria. Eur J Pediatr 1991;150:425-428.

4 Schulpis KH, Nounopoulos C, Scarpalezou A, Bouloukos A, Missiou-Tsagarakis S: Serum carnitine level in phenylketonuric children under dietary control in Greece. Acta Paediatr Scand 1990;79:930-934.
5 Infante JP, Huszagh VA: Impaired arachidonic (20:4n-6) and docosahexaenoic (22: 6n-3) acid synthesis by phenylalanine metabolites as etiological factors in the neuropathology of phenylketonuria. Mol Genet Metab 2001;72:185-198. 
6 Rebouche CJ, Bosch EP, Chenard CA, Schabold KJ, Nelson SE: Utilization of dietary precursors for carnitine synthesis in human adults. J Nutr 1989;119:1907-1913.

7 Chace DH, Kalas TA, Naylor EW: Use of tandem mass spectrometry for multianalyte screening of dried blood specimens from newborns. Clin Chem 2003;49:1797-1817.

8 Weigel C, Rauh M, Kiener C, Rascher W, Knerr I: Effects of various dietary amino acid preparations for phenylketonuric patients on the metabolic profiles along with postprandial insulin and ghrelin responses. Ann Nutr Metab 2007;51:352-358.
9 Stadler DD, Chenard CA, Rebouche CJ: Effect of dietary macronutrient content on carnitine excretion and efficiency of carnitine reabsorption. Am J Clin Nutr 1993;58:868872.

10 Lombard KA, Olson AL, Nelson SE, Rebouche CJ: Carnitine status of lactoovovegetarians and strict vegetarian adults and children. Am J Clin Nutr 1989;50:301-306.
11 Rebouche CJ: Kinetics, pharmacokinetics, and regulation of L-carnitine and acetyl-Lcarnitine metabolism. Ann NY Acad Sci 2004;1033:30-41.

12 Van Vlies N, Ofman R, Wanders RJ, Vaz FM: Submitochondrial localization of 6-N-trimethyllysine dioxygenase - implications for carnitine biosynthesis. FEBS J 2007;274: 5845-5851.

13 Chen W, Huang YC, Shultz TD, Mitchell ME: Urinary, plasma, and erythrocyte carnitine concentrations during transition to a lactoovovegetarian diet with vitamin B-6 depletion and repletion in young adult women. Am J Clin Nutr 1998;67:221-230. 